\title{
Ten-year-old boy with finger and toe swelling
}

\author{
Eleni E. Drakonaki • K. M. Bradley • Z. A. Khan • \\ C. Patel • D. J. Wilson
}

Received: 30 January 2011 /Revised: 28 September 2011 /Accepted: 19 October 2011 /Published online: 23 November 2011

(C) ISS 2011

\section{0-year-old boy with finger and toe swelling}

A 10-year-old boy was admitted complaining of weight loss and progressive wrist and finger swelling over the past 3 months. On physical examination, there was swelling of the wrists, ankles, fingers and toes. Radiographs of the hands and feet were performed (Fig. 1).
Fig. 1 Anteroposterior plain radiographs of the hands and feet
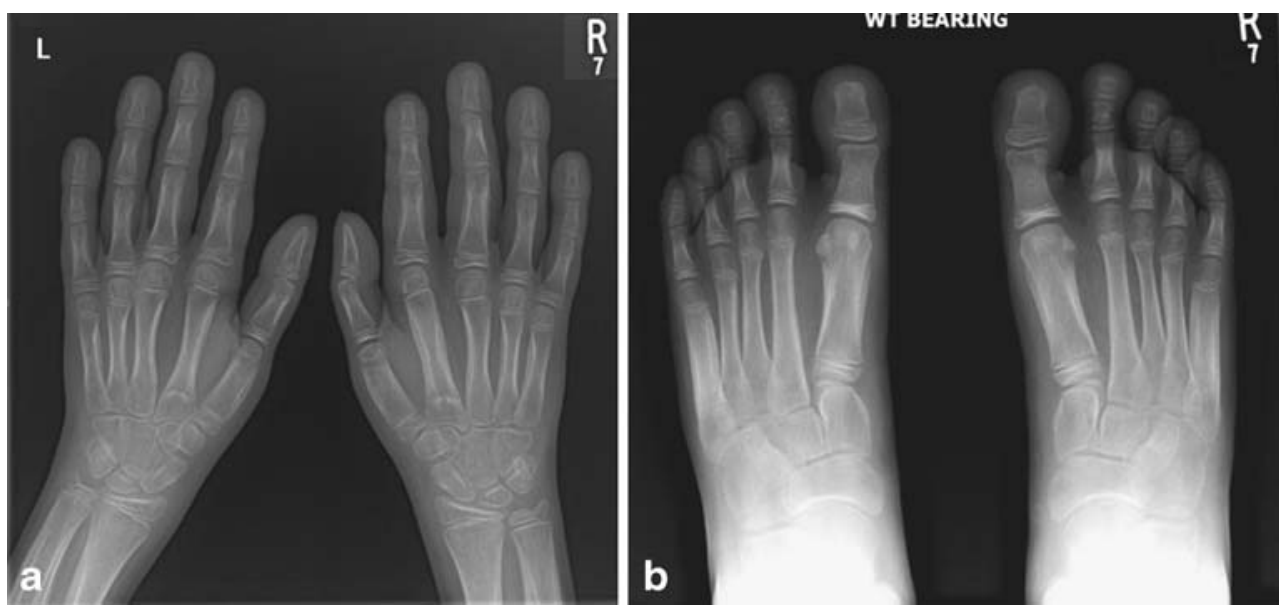

The diagnosis can be found at doi:10.1007/s00256-011-1317-x.

E. E. Drakonaki $\cdot$ D. J. Wilson

Department of Radiology, Nuffield Orthopaedic Centre,

John Radcliff Hospitals NHS Trust,

Headington, OX3 7LD, Oxford, UK

E. E. Drakonaki $(\triangle) \cdot$ K. M. Bradley $\cdot$ Z. A. Khan $\cdot$ C. Patel

PET-CT Department, Churchill Cancer Centre,

John Radcliff Hospitals NHS Trust,

Headington, OX3 7LD, Oxford, UK

e-mail: drakonaki@yahoo.gr 